\title{
Effect of a Minor Sr Modifier on the Microstructures and Mechanical Properties of 7075 T6 Al Alloys
}

\author{
Shaoming Ma ${ }^{1,2}$, Youhong Sun ${ }^{1,2, *}$, Huiyuan Wang ${ }^{3}$, Xiaoshu Lü ${ }^{1,4}$, Ming Qian ${ }^{1}$, \\ Yinlong Ma ${ }^{1,3}$, Chi Zhang ${ }^{1,3}$ and Baochang Liu ${ }^{1,2}$ \\ 1 School of Construction Engineering, Jilin University, Changchun 130026, China; \\ masm14@mails.jlu.edu.cn (S.M.); xiaoshu.lu@aalto.fi (X.L.); mqian@jlu.edu.cn (M.Q.); \\ ylma@jlu.edu.cn (Y.M.); zhangchi15@mails.jlu.edu.cn (C.Z); liubc@jlu.edu.cn (B.L.) \\ 2 Key Laboratory of Drilling and Exploitation Technology in Complex Conditions, \\ Ministry of Land and Resources, China No. 938 Ximinzhu Street, Changchun 130026, China \\ 3 Key Laboratory of Automobile Materials of Ministry of Education \& School of Materials Science and \\ Engineering, Jilin University, No. 5988 Renmin Street, Changchun 130025, China; wanghuiyuan@jlu.edu.cn \\ 4 Department of Civil and Structural Engineering, School of Engineering, Aalto University, \\ Helsinki 02015, Finland \\ * Correspondence: syh@jlu.edu.cn; Tel./Fax: +86-431-8516-6402
}

Academic Editor: Hugo F. Lopez

Received: 19 October 2016; Accepted: 26 December 2016; Published: 6 January 2017

\begin{abstract}
The influence of a minor strontium (Sr) modifier on the microstructures and mechanical properties of $7075 \mathrm{Al}$ alloys was investigated in this paper. The grain size of cast $7075 \mathrm{Al}$ alloys was refined from $157 \mu \mathrm{m}$ to $115 \mu \mathrm{m}, 108 \mu \mathrm{m}$, and $105 \mu \mathrm{m}$ after adding $0.05 \mathrm{wt}$. \%, $0.1 \mathrm{wt} \%$, and 0.2 wt. \% Sr, respectively. The extruded $7075 \mathrm{Al}$ alloys was refined with different degrees of Sr modifier. The mechanical properties were optimum when adding $0.1 \mathrm{wt}$. \% Sr. The ultimate tensile strength $\left(\sigma_{\mathrm{b}}\right)$ increased from 573 to $598 \mathrm{MPa}$ and the elongation-to-failure $\left(\delta_{\mathrm{f}}\right)$ was raised from $19.5 \%$ to $24.9 \%$. The microhardness increased from 182 to $195 \mathrm{Hv}$. The tensile fracture surface via scanning electron microscopy (SEM) revealed a transition from brittle fracture to ductile fracture as Sr increased from $0 \mathrm{wt}$. \% to $0.2 \mathrm{wt}$. \%. The result in this paper proved that the modifier can improve the properties of $7075 \mathrm{Al}$ alloy.
\end{abstract}

Keywords: 7075 Aluminum alloy; Sr modifier; mechanical properties

\section{Introduction}

The insufficient mechanical properties of conventional steel drill pipes pose a challenge to the deep and ultra-deep well industry because of the high density of steel. High-strength aluminum alloys, such as 7075 and $2024 \mathrm{Al}$ alloy, are preferred over steel for making drill pipes for deep oil and gas wells due to their better strength to weight ratio, lower stiffness, and higher corrosion resistance [1,2]. At present, aluminum alloy drilling pipes (ADP) have been proved promising for making drilling pipes worldwide, especially in countries such as America, Japan, France, and Russia. ADP has been successfully applied in some world record deep wells, such as SG-3 in Russia, the BD-04A well in Qatar, and the OP-11well on Sakhalin Island.

The $7075 \mathrm{Al}$ alloy, which is one of the 7000 series $(\mathrm{Al}-\mathrm{Zn}-\mathrm{Mg}-\mathrm{Cu})$ ultra-high strength alloys, have been extensively used for structural components in aerospace and automobile industries $[3,4]$. Generally, the casting methods to produce $7075 \mathrm{Al}$ alloy are simple and economical due to the possibility of utilizing conventional casting equipment without limitation in size and shape of the components [5]. Fine-grain strengthening during casting, including ultrasonic vibrations [6,7], electromagnetic stirring [8], and modification [9], is a good way to simultaneously achieve higher tensile strength and ductility for alloys at present. 
Modification during casting is a simple and effective way to control grain size, through which the growth of crystal is inhibited by poisoning its surface with the help of certain modifying elements and, thus, refine the grain size. It is advantageous for increasing the tensile strength and ductility at the same time after extrusion by decreasing the grain size during casting. In 1921, Pacz [9] first applied modified treatment to melted Al-Si alloys with alkali fluoride. For the last decades, modification with other elements has been widely applied for grain refinement, plasticity improvement, phase transformation, and many other fields [10-13]. Sr, which is in the form of conventional Al-10Sr master alloy, exhibits a relatively good and long-lasting modification effect and has, therefore, been extensively studied in both $\mathrm{Al}$ and $\mathrm{Mg}$ alloys [14-17]. It is well known that the microstructures of Al-10Sr master alloy is composed of $\alpha$ - $\mathrm{Al}$ and $\mathrm{Al}_{4} \mathrm{Sr}$ phase which is a body-centered tetragonal structure $(a=4.46 \AA$ and $c=11.07 \AA$ ) [17]. However, $\mathrm{Al}_{4} \mathrm{Sr}$ phase could not directly influence the refinement unless the free Sr could be obtained by the dissolution of the phase [18]. Unfortunately, to the best of our knowledge, there are only a few reports on the modification effect of Sr on $7075 \mathrm{Al}$ alloy $[19,20]$.

The goal of the present study is to clarify whether Sr modification has effect on the microstructures and mechanical properties of $7075 \mathrm{Al}$ alloy, then reveal the reinforcement mechanism of the $\mathrm{Sr}$ modifier preliminarily. It is expected that the results could be helpful in promoting the development of high-strength $7075 \mathrm{Al}$ alloy, thus providing guidance for manufacturing high-strength aluminum alloy drilling pipes for ultra-deep exploration, as well as other industries.

\section{Experimental Procedure}

Commercial $7075 \mathrm{Al}$ alloy ingots and $\mathrm{Al}-10 \mathrm{Sr}$ master alloy rod were used as starting materials to prepare experimental alloys. First, a $2.5 \mathrm{~kg}$ commercial $7075 \mathrm{Al}$ alloy ingot was melted at $720{ }^{\circ} \mathrm{C}$ for $10 \mathrm{~min}$ in a clay crucible in an electric resistance furnace of $5 \mathrm{~kW}$. Then $\mathrm{Al}-10 \mathrm{Sr}$ preheated at $200^{\circ} \mathrm{C}$ in the box-type resistance furnace was added to the melt. The melts were manually stirred for about 2 min using a stainless steel impeller to facilitate incorporation and uniform distribution of $\mathrm{Al}-10 \mathrm{Sr}$ in melts. After that, the melts were held at $720^{\circ} \mathrm{C}$ for about $20 \mathrm{~min}$, during which time the melts were stirred every $5 \mathrm{~min}$ and deslagged before finally being poured into a cylindrical steel mold which had been preheated at $200{ }^{\circ} \mathrm{C}$ to produce $7075-\mathrm{Sr}$ alloy with the primary sample size of $90 \mathrm{~mm}$ in diameter and $100 \mathrm{~mm}$ in height. The 7075 alloy with different $\mathrm{Sr}$ contents were prepared in the same way by adding different amount of Al-10Sr. The designed composition of $\mathrm{Sr}$ in melts were $0,0.05 \mathrm{wt}$. \%, 0.1 wt. $\%$, and 0.2 wt. $\%$.

Cylinder samples with diameter of $90 \mathrm{~mm}$ and height of $100 \mathrm{~mm}$ were prepared for extrusion process. The samples were homogenized at $460{ }^{\circ} \mathrm{C}$ for $6 \mathrm{~h}$, and then extruded at $480{ }^{\circ} \mathrm{C}$ to obtain $40 \mathrm{~mm} \times 5 \mathrm{~mm}$ plates. After that the samples were solution treated at $470{ }^{\circ} \mathrm{C}$ for $1 \mathrm{~h}$ and then aged at $120{ }^{\circ} \mathrm{C}$ for $24 \mathrm{~h}$. Metallographic samples of cast sample with a size of $10 \mathrm{~mm} \times 10 \mathrm{~mm} \times 10 \mathrm{~mm}$ and the ND-TD (normal direction-transverse direction) of extruded T6 heat-treated $7075 \mathrm{Al}$ alloy with a size of $10 \mathrm{~mm} \times 10 \mathrm{~mm} \times 4 \mathrm{~mm}$ were prepared in accordance with standard procedures used for metallographic preparation of metal samples. Then the samples were etched with Keller reagent $\left(1.0 \mathrm{~mL} \mathrm{HF}+1.5 \mathrm{~mL} \mathrm{HCl}+2.5 \mathrm{~mL} \mathrm{HNO}_{3}+95 \mathrm{~mL} \mathrm{H}_{2} \mathrm{O}\right)$ for about $15 \mathrm{~s}$ at room temperature. The microstructures and phase were investigated by optical microscopy $(\mathrm{OM})$ (Carl Zeiss-Axio Imager $\mathrm{A}_{2} \mathrm{~m}$, Gottingen, Germany). The statistics grain size is obtained by the Nano Measure 2.1 (SJTU, Shanghai, China) and simply fitted with a Gaussian curve with Origin 8.0 software (OriginLab, Hampton, MA, USA). The scanning electron microscopy (SEM) (ZEISS EVO18, Mainz, Germany) fitted an Oxford Inca energy dispersive spectrometer (EDS) (Oxford Instruments, Oxon, London, UK) for further microanalysis. Phase constituents of extruded T6 samples were analyzed by X-ray diffraction (XRD) (D/Max 2500PC, Rigaku, Tokyo, Japan) using Cu K $\alpha$ radiation in step mode from $20^{\circ}$ to $80^{\circ}$ with a scanning speed of $4^{\circ} / \mathrm{min}$. Thermal analysis was carried out using a SDT-Q600 differential scanning calorimeter (DSC) apparatus (TA Instruments Inc., New Castle, PA, USA) to obtain the freezing temperature of alpha-Al and secondary phases of the extruded samples at a cooling rate of $10{ }^{\circ} \mathrm{C} / \mathrm{min}$. Samples of the material $(30 \mathrm{mg})$ were put into an alumina pan and then heated to 
$700{ }^{\circ} \mathrm{C}$ and then cooling at $10{ }^{\circ} \mathrm{C} / \mathrm{min}$ under air atmosphere. The dimensions and morphologies of the precipitates are only a few tens of nanometer which can only be revealed by the Transmission electron microscopy (TEM) technique (JEM-2100, JEOL, Tokyo, Japan) equipped with an EDS analyzer (Oxford Instruments, London, UK). TEM sample preparation was performed by successive mechanical grinding, with an operated voltage of $200 \mathrm{kV}$.

The tensile strength and fracture elongation were tested at room temperature by an electronic universal test machine (DDL 100, CIMACH, Changchun, China) at the speed of $0.18 \mathrm{~mm} / \mathrm{min}$. The tensile specimens were obtained parallel to the extruding direction, and at least three specimens were tested for each condition. The 7075 with 0.1 wt. \% Sr sample was analyzed by SEM (Hitachi S-4800, Tokyo, Japan) and electron backscatter diffracting (EBSD) (NordlysNano, London, UK). The fracture morphology was observed by SEM (EVO18, ZEISS, Mainz, Germany) and the microhardness of extruded 7075 T6 Al alloy were tested by a microhardness tester (1600-5122VD Microment 5104, Buehler Ltd., Chicago, IL, USA) under an applied load of $50 \mathrm{~g}$ for $15 \mathrm{~s}$ on the Al matrix. At least seven measurements were done for each condition to ensure the accuracy of results.

\section{Results and Discussion}

As-cast microstructures of 7075 alloys without and with 0.05 wt. \%, 0.1 wt. \%, and 0.2 wt. \% of Sr addition are shown in Figure 1a-d. The grain size distribution is obtained from OM images by Nano Measure 2.1 (SJTU, Shanghai, China) and fitted by Origin 8.0 software (OriginLab, Hampton, MA, USA) with a Gaussian curve (seen in the inset of Figure 1). As can be seen, the grain size decreases by different degree after adding minor Sr modifier. The refined grain can benefit for improving the mechanical properties of extruded $7075 \mathrm{Al}$ alloy subsequently. As the alloys have not been solution or aging heat-treated, no $\mathrm{MgZn} \mathrm{n}_{2}$ can be found in the $\mathrm{OM}$ microstructures.

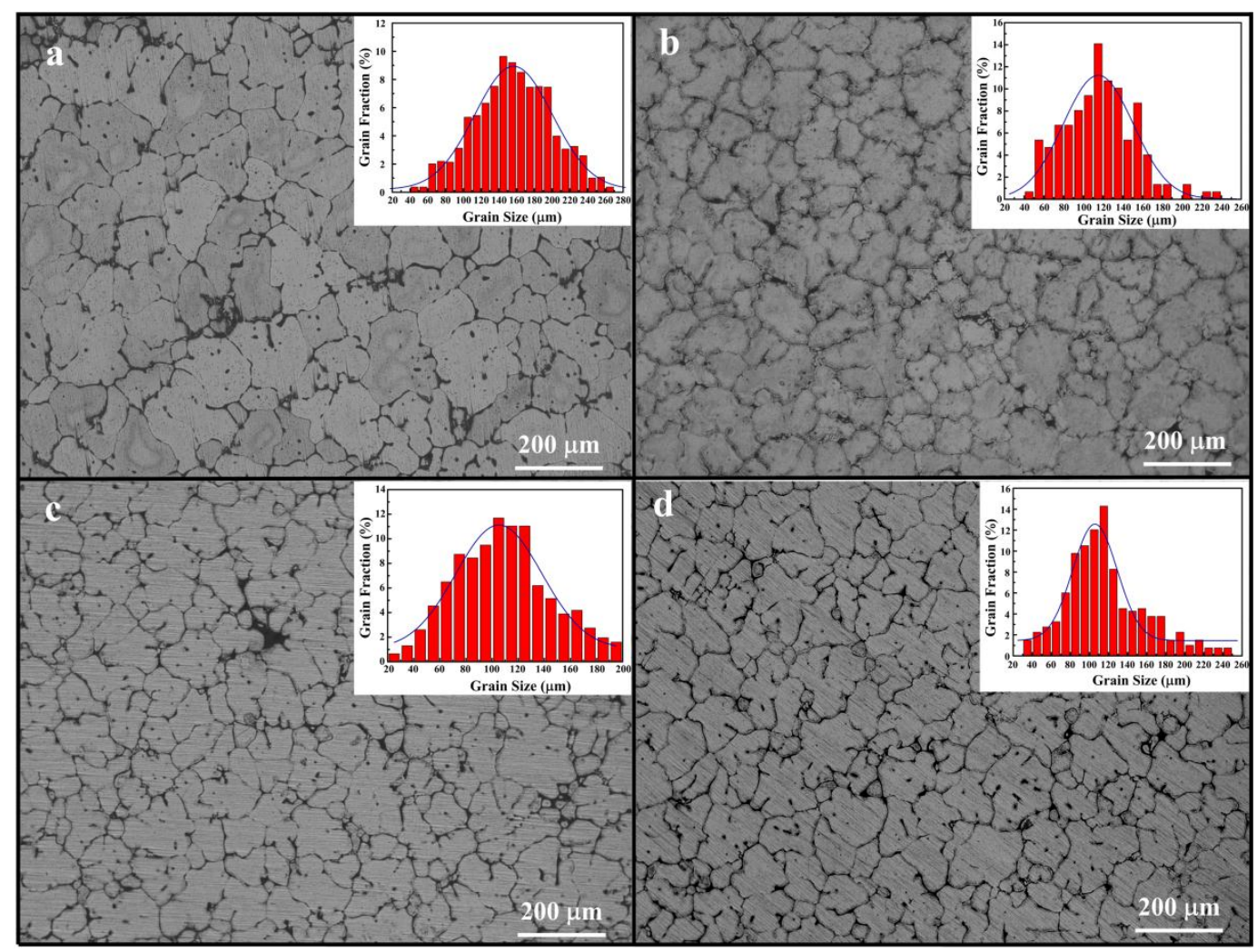

Figure 1. OM microstructures of as-cast $7075 \mathrm{Al}$ alloys without and with various contents of Sr addition: (a) 0 ; (b) 0.05 wt. \%; (c) 0.1 wt. \%; and (d) 0.2 wt. \% Sr (The grain size distribution is obtained from OM images by Nano Measure 2.1 and fitted by Origin 8.0 software with a Gaussion curve). 
Figure 2 shows the change of the mean grain size of as-cast $7075 \mathrm{Al}$ without and with different contents of Sr based on the statistical result of Figure 1. By adding $0.05 \mathrm{wt}$. \%, $0.1 \mathrm{wt}$. \%, and 0.2 wt. \% Sr, the mean grain size of $7075 \mathrm{Al}$ reduces from $157 \mu \mathrm{m}$ to $115 \mu \mathrm{m}, 108 \mu \mathrm{m}$, and $105 \mu \mathrm{m}$ respectively. The equation to measure grain size in Nano Measure 2.1 is:

$$
F=\frac{\sum_{N=1}^{N} 4 \pi A / P^{2}}{N}
$$

where $A$ and $P$ are the area and perimeter of the grains, respectively, and $N$ is the number of grains. For each sample, measurements are taken from the 100 times magnified images.

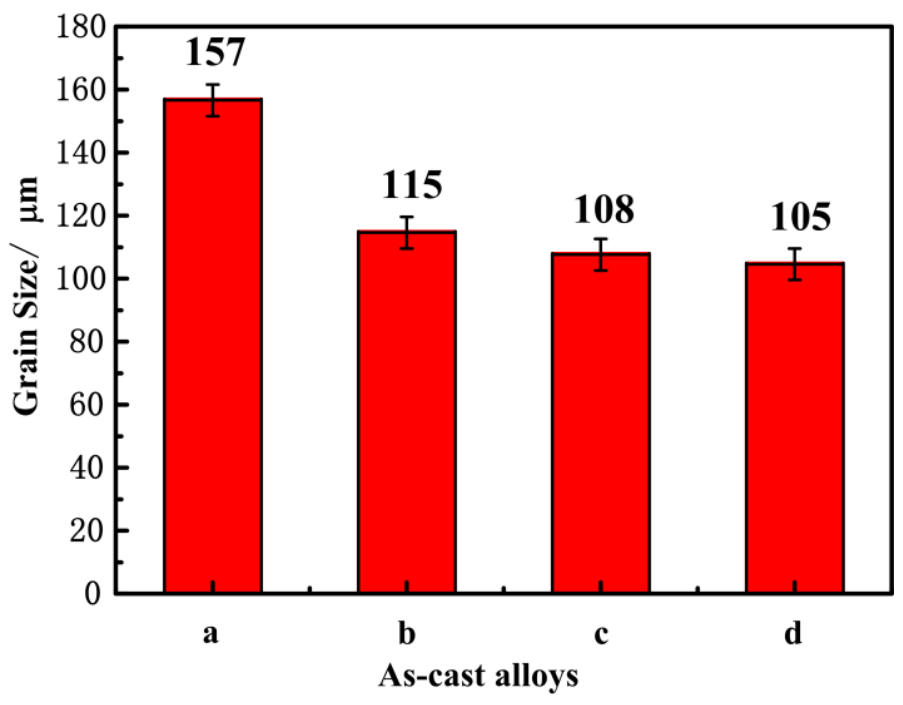

Figure 2. The change of the mean grain size of as-cast $7075 \mathrm{Al}$ alloys without and with various contents of Sr addition: (a) 0 wt. \%; (b) 0.05 wt. \%; (c) 0.1 wt. \%; and (d) 0.2 wt. \% Sr.

Figure 3a-d shows the microstructures of ND-TD surface of extruded $7075 \mathrm{~T} 6 \mathrm{Al}$ alloys without and with different contents of Sr (0.05 wt. \%, $0.1 \mathrm{wt} . \%$ and $0.2 \mathrm{wt}$. \%). After extrusion and T6 heat treatment, the globular grains of the alloys are compressed to lamella in the ND-TD direction. The thickness of $\alpha$-Al lamella and the sizes of strength phase ( $\left.\mathrm{AlCuMg}, \mathrm{MgZn}_{2}\right)$ decrease and are better distributed (Figure 3b-d) than $7075 \mathrm{Al}$ alloy without modification (Figure 3a).

Figure 4 shows the SEM images of $7075 \mathrm{Al}$ alloys without and with various contents Sr addition. The precipitates are identified as AlCuMg by EDS with a size of $\sim 1-5 \mu \mathrm{m}$, which agrees well with the result of OM in Figure 3. It is well known that when the $\mathrm{Zn:Mg}$ ratios are between 1:2 and 1:3 in the 7075 aluminum alloys, $\mathrm{MgZn}_{2}$ precipitates are produced at aging temperatures below $200{ }^{\circ} \mathrm{C}$ and are the main strengthening factor in 7075 alloys [19], so further experiments are needed to prove the existence of $\mathrm{MgZn}_{2}$.

The TEM micrographs of $7075 \mathrm{Al}$ alloys after T6 treatment with 0.1 wt. \% Sr are shown in Figure 5. We found that only the finer dark portion $(\sim 30-100 \mathrm{~nm})$ is $\mathrm{MgZn}_{2}$. A great amount of polygon $\mathrm{MgZn} \mathrm{n}_{2}$ precipitates are found in both samples. It has been concluded that Orowan dislocation bypassing is the operative mechanism, and the increase in strength can be determined [21]. It can be seen that the precipitation plays a key role in strengthening the alloy. Some coarse phases in the grains makes parts of precipitates transform and grow, which is beneficial for the ductility of the specimen [22,23]. However, the relationship between the size of $\mathrm{MgZn}_{2}$ and the ultimate tensile strength is not discussed in this paper. 


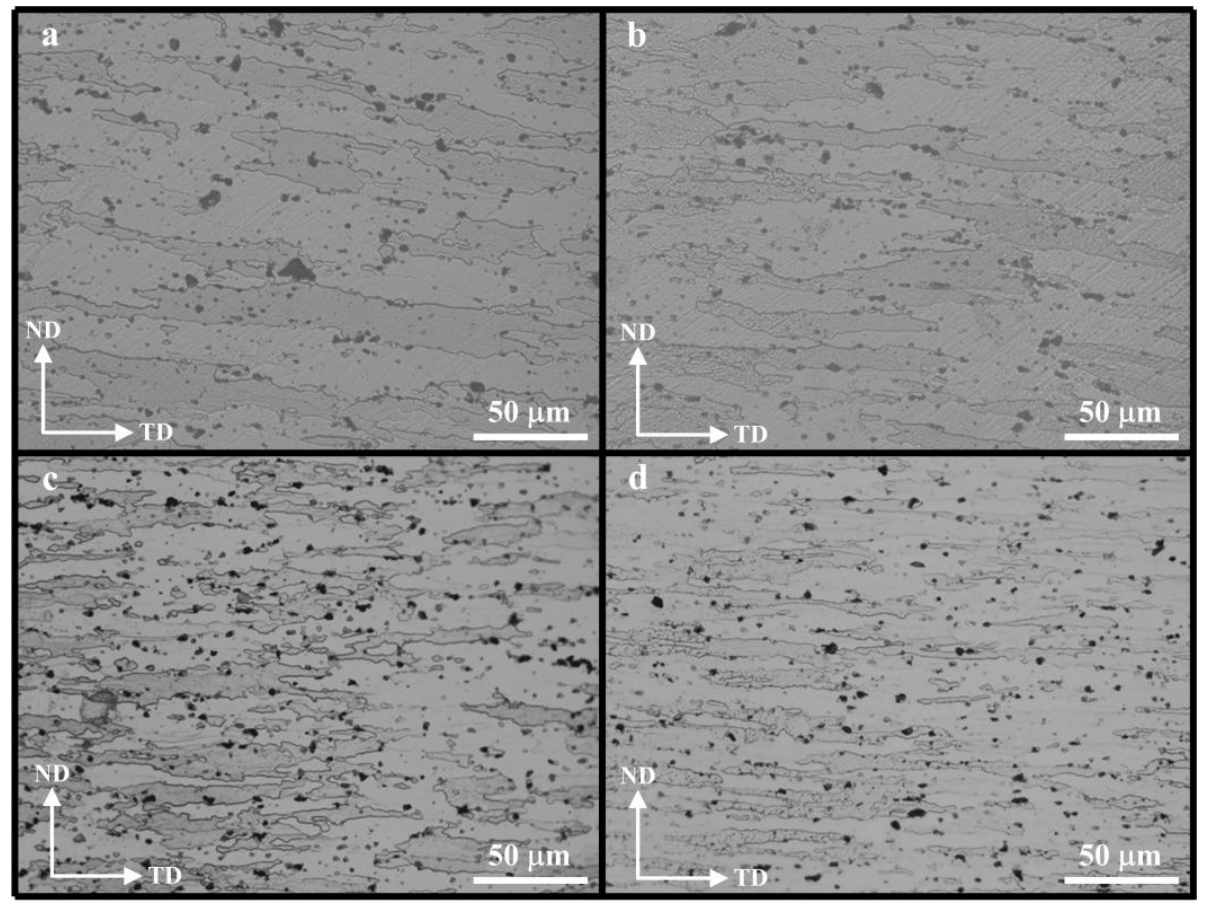

Figure 3. OM microstructures of ND-TD surface for $7075 \mathrm{~T} 6$ alloy without and with different contents of Sr addition: (a) 0 wt. \%; (b) 0.05 wt. \%; (c) 0.1 wt. \%; and (d) 0.2 wt. \% Sr.

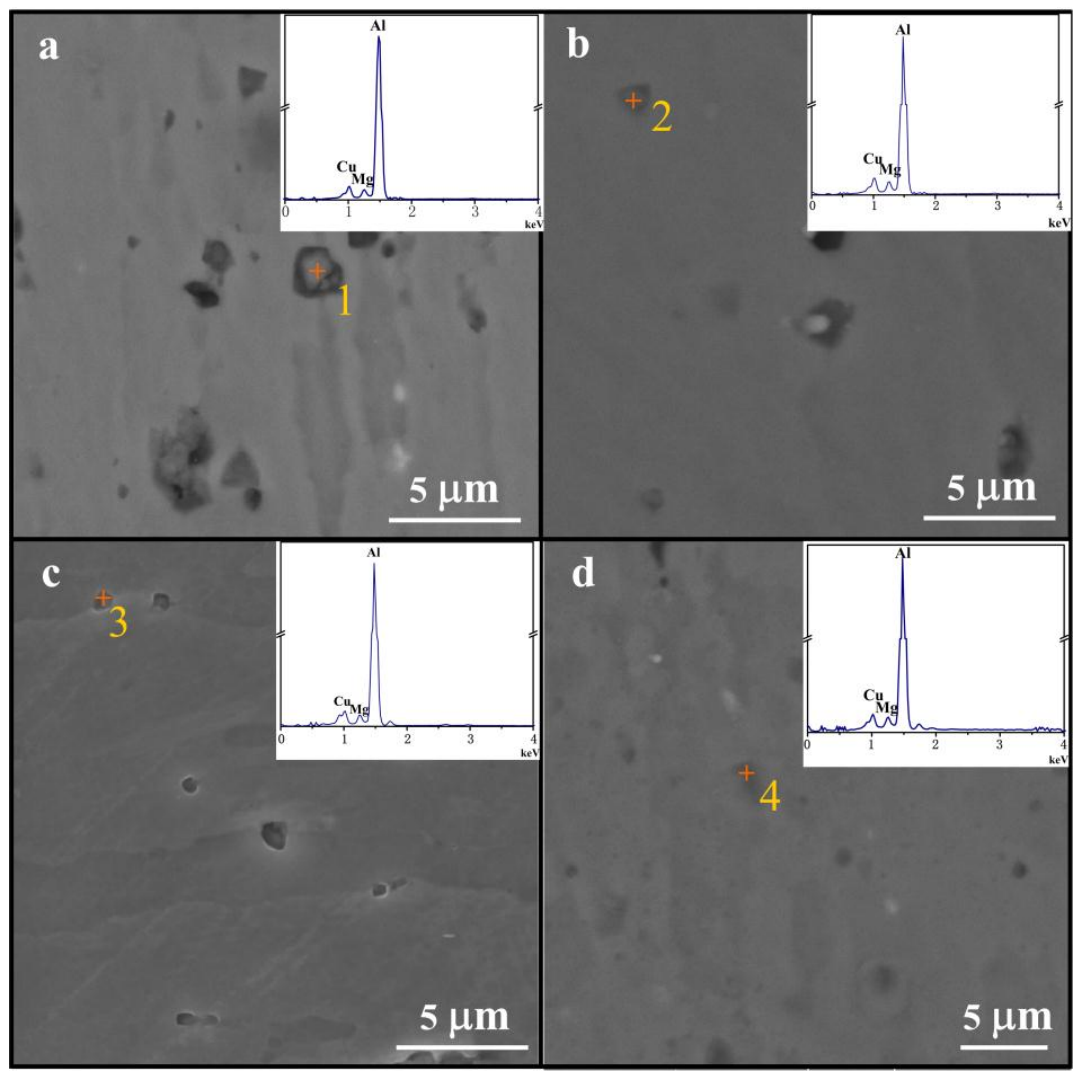

Figure 4. The SEM images of $7075 \mathrm{Al}$ alloys without and with various contents Sr addition: (a) 0 wt. \%; (b) 0.05 wt. \%; (c) 0.1 wt. \%; and (d) 0.2 wt. \% Sr (the inserts are EDS results for strengthen phases) 


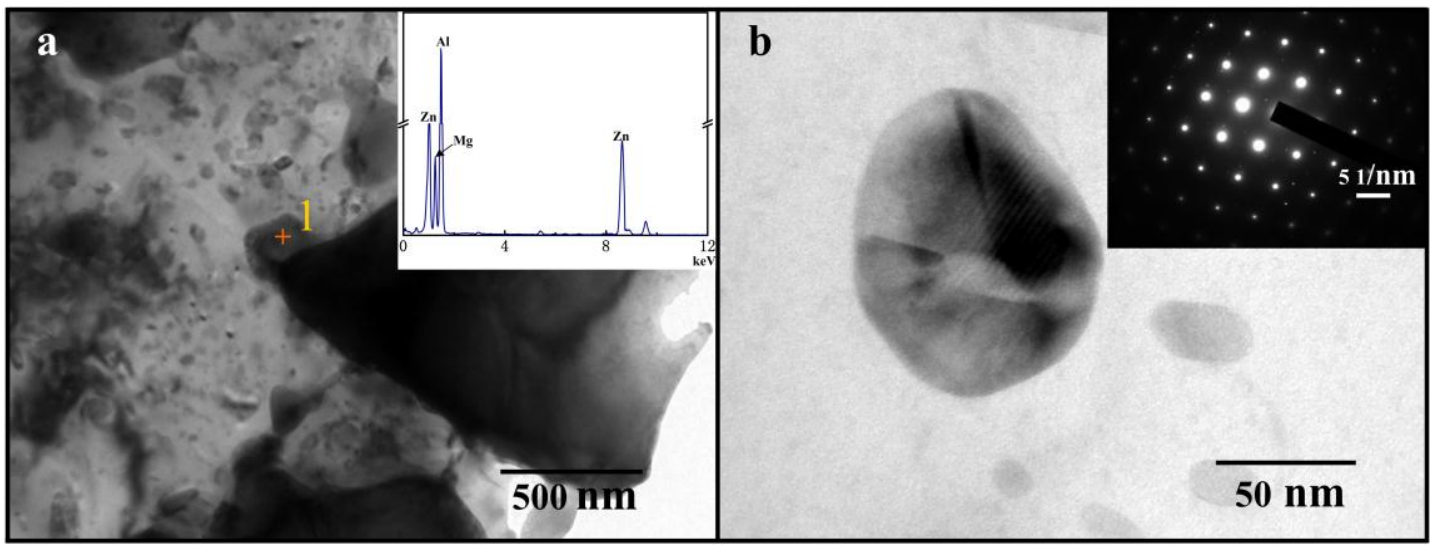

Figure 5. The TEM images of $7075 \mathrm{Al}$ alloys without (a) and with $0.1 \mathrm{wt}$. \% Sr (b).

Figure 6 shows the DSC curves of the 7075 T6 aluminum sample without and with 0.05 wt. \%, $0.1 \mathrm{wt}$ \%, and $0.2 \mathrm{wt}$. \% Sr. Based on the DSC curves, the solidification temperatures of $\alpha$-Al were 634 , 631,630 , and $629^{\circ} \mathrm{C}$, respectively, which may indicate an increase in undercooling with the addition of Sr. Barrirero et al. has proved that the Sr promote the formation of ternary compound nanometre-sized clusters at the Si/liquid interface near the binary eutectic phase by APT method. They observed that, ahead of the growing Si crystal, a diffusion profile is formed by segregation leading to constitutional undercooling, thus altering the microstructure and obtained finer grain sizes [24]. The microstructural refinement observed in the present study can be attributed to the fact that $\mathrm{Sr}$ increased undercooling of the alloys and interacted with the growing $\alpha-\mathrm{Al}$.

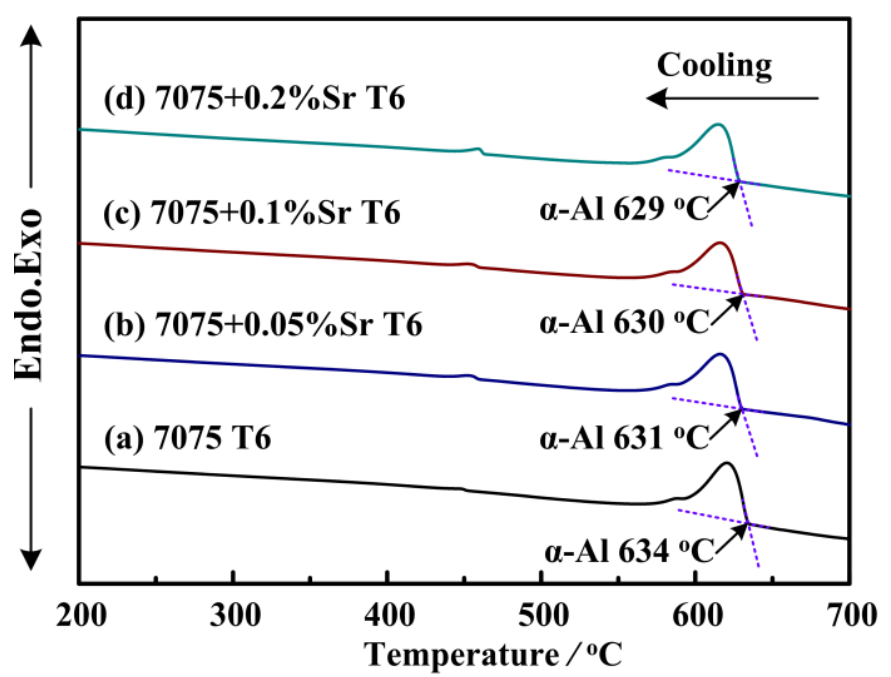

Figure 6. DSC curves for $7075 \mathrm{Al}$ T6 heat treated samples with various contents of Sr: (a) 0 wt. \%; (b) 0.05 wt. \%; (c) 0.1 wt. \%; and (d) 0.2 wt. \% Sr.

The constitutional undercooling usually promotes structural refinement [25]. The growth of $\alpha$-Al is accompanied by the adsorption of $\mathrm{Sr}$ to the steps of a solid-liquid interface. Sr prevents $\mathrm{Al}$ atoms from attaching to their crystallographic sites and, thus, hinders the growth of the preferential direction, namely the $<100>$ crystal orientation. As a consequence, the grain size is refined and the mechanical properties are improved. The effect of Sr contents on the grain size of extruded $7075 \mathrm{~T} 6$ alloy agrees well with the results of the as-cast alloys, even though the grain of $7075 \mathrm{Al}$ changed from nearly globular to lamellar after extrusion. 
In order to elucidate the effect of minor $\mathrm{Sr}$ addition on the mechanical properties of $7075 \mathrm{~T} 6 \mathrm{Al}$ alloys, tensile tests are performed for the extruded $7075 \mathrm{~T} 6 \mathrm{Al}$ alloys. Figure 7 presents the engineering stress-engineering strain curves of extruded 7075 T6 Al alloy without and with different Sr additions at room temperature.

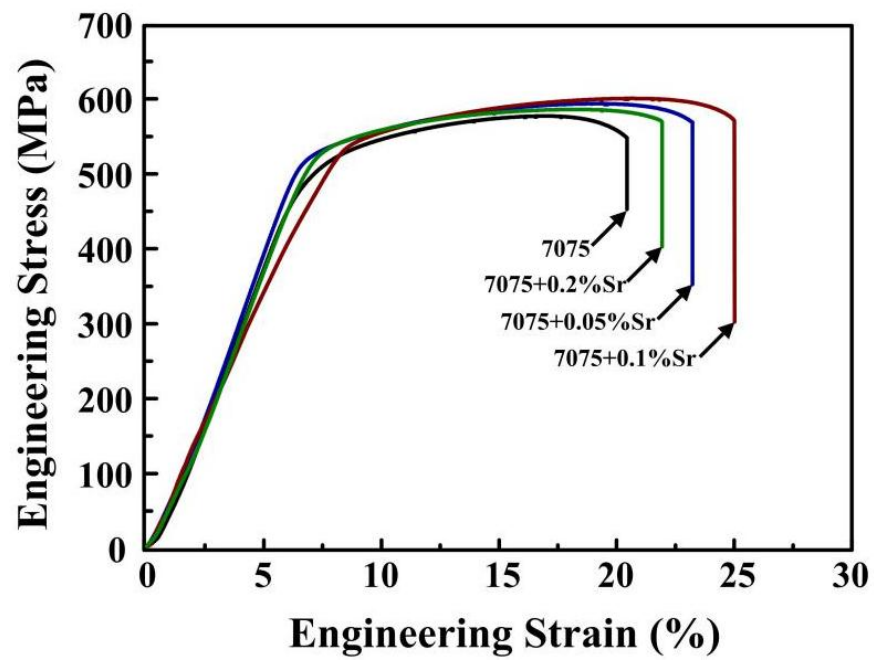

Figure 7. Engineering stress-stain curves of 7075 T6 alloy without and with different contents of Sr (wt. \%).

Other mechanical properties such as average yield strength, ultimate tensile strengths, elongation, elongations-to-fracture, and the microhardness are shown in Table 1 . From Table 1 we can see that the mechanical properties of the alloy are improved when $\mathrm{Sr}$ addition increased from $0 \mathrm{wt}$. \% to $0.1 \mathrm{wt}$. \%, but the improvement is subsequently degraded as the $\mathrm{Sr}$ addition reaches $0.2 \mathrm{wt}$. \%. The tensile yield strengths, tensile strengths, elongation, and microhardness achieve their maximum value with 0.1 wt. \% Sr addition. The yield strength and ultimate tensile strength increase from 490 to $526 \mathrm{MPa}$ and from 573 to $598 \mathrm{MPa}$, respectively. Elongation and fracture elongation increase from $11.4 \%$ to $11.7 \%$ and from $19.5 \%$ to $24.9 \%$, respectively. Microhardness improves from 182 to $195 \mathrm{Hv}$. In a word, $0.1 \mathrm{wt}$ \% $\%$ Sr can achieve the optimal modification effect for $7075 \mathrm{Al}$ alloys. Our tensile strength is higher than the result reported by Chen et al. [26], as they gave a true stress-strain curve in their research with a true stress of about $600 \mathrm{MPa}$. The microhardness of $195 \mathrm{HV}$ is the same value with the research reported by $\mathrm{M}$. Tajally et al. [27], which is supplied by Alcoa, USA. However, their tensile strength is only $370 \mathrm{MPa}$.

Table 1. Mechanical properties of 7075 T6 alloys without and with different contents of Sr (wt. \%).

\begin{tabular}{cccccc}
\hline Sample & $\boldsymbol{\sigma}_{\mathbf{s}} / \mathbf{M P a}$ & $\boldsymbol{\sigma}_{\mathbf{b}} / \mathbf{M P a}$ & $\boldsymbol{\delta} / \%$ & $\boldsymbol{\delta}_{\mathbf{f}} / \%$ & Hardness/Hv \\
\hline 7075 & $490_{-7}^{+9}$ & $573_{-1}^{+3}$ & $11.4_{-0.1}^{+0.1}$ & $19.5_{-0.9}^{+0.9}$ & $182_{-7}^{+2}$ \\
$7075+0.05 \% \mathrm{Sr}$ & $516_{-3}^{+8}$ & $590_{-2}^{+1}$ & $11.6_{-0.2}^{+0.1}$ & $23.2_{-0.9}^{+0.2}$ & $193_{-0}^{+1}$ \\
$7075+0.1 \% \mathrm{Sr}$ & $526_{-7}^{+4}$ & $598_{-2}^{+1}$ & $11.7_{-0.2}^{+0.1}$ & $24.9_{-0.8}^{+0.4}$ & $195_{-2}^{+1}$ \\
$7075+0.2 \% \mathrm{Sr}$ & $514_{-9}^{+5}$ & $582_{-4}^{+3}$ & $11.5_{-0.2}^{+0.2}$ & $21.0_{-0.1}^{+1.0}$ & $189_{-1}^{+1}$ \\
\hline
\end{tabular}

The XRD patterns of the ND-TD surface for extruded $7075 \mathrm{~T} 6 \mathrm{Al}$ alloys without and with different Sr addition are shown in Figure 8a-d. According to XRD results in Figure 8, only Al is identified by $\mathrm{XRD}$ in alloys without and with $\mathrm{Sr}$ addition. $\mathrm{No} \mathrm{MgZn}_{2}$ ( $\eta$ phase) and $\mathrm{Al}_{4} \mathrm{Sr}$ are found after adding different $\mathrm{Sr}$ to $7075 \mathrm{Al}$ alloys. The result reveals that the addition of different contents of Sr has no obvious influence on phase compositions of the alloy. The possible reason may be that the XRD technique is not sensitive enough for studying the low content of $\mathrm{MgZn}_{2}$ and $\mathrm{Al}_{4} \mathrm{Sr}$ intermetallic 
phases. Some $\mathrm{Zn}$ and $\mathrm{Mg}$ atoms dissolving in the $\mathrm{Al}$ matrix, thus, the content of nanosized $\mathrm{MgZn}_{2}$ was too small to be detected.

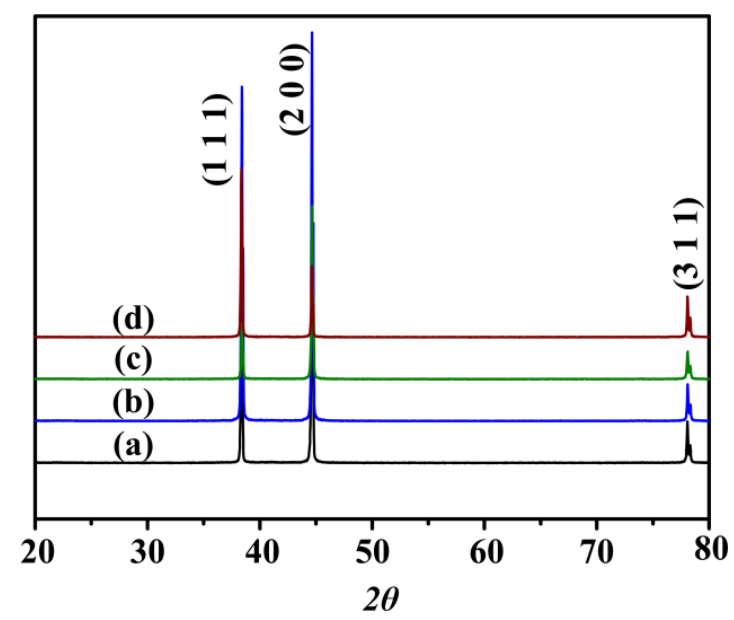

Figure 8. XRD results of ND-TD surface for $7075 \mathrm{~T} 6$ alloy without and with different contents of $\mathrm{Sr}$ addition: (a) 0 wt. \%; (b) 0.05 wt. \%; (c) 0.1 wt. \%; and (d) 0.2 wt. \% Sr.

To clarify the mechanism of Sr addition improving the mechanical properties of extruded $7075 \mathrm{~T} 6$ $\mathrm{Al}$ alloy, the sample with $0.1 \mathrm{wt}$. \% Sr addition is analyzed by EBSD.

Figure 9 shows the EBSD image of as-cast $7075 \mathrm{~T} 6 \mathrm{Al}$ alloys without and with $0.1 \mathrm{wt}$. \% Sr. $\mathrm{Al}_{4} \mathrm{Sr}$ (yellow dot in the image) is detected both in grain boundary and grain interior (seen in Figure $9 \mathrm{~b}$ ) in the sample contained $0.1 \mathrm{wt}$. \% Sr. This result indicate that minor $\mathrm{Al}_{4} \mathrm{Sr}$ is formed when adding 0.1 wt. \% Sr in $7075 \mathrm{Al}$ alloy.

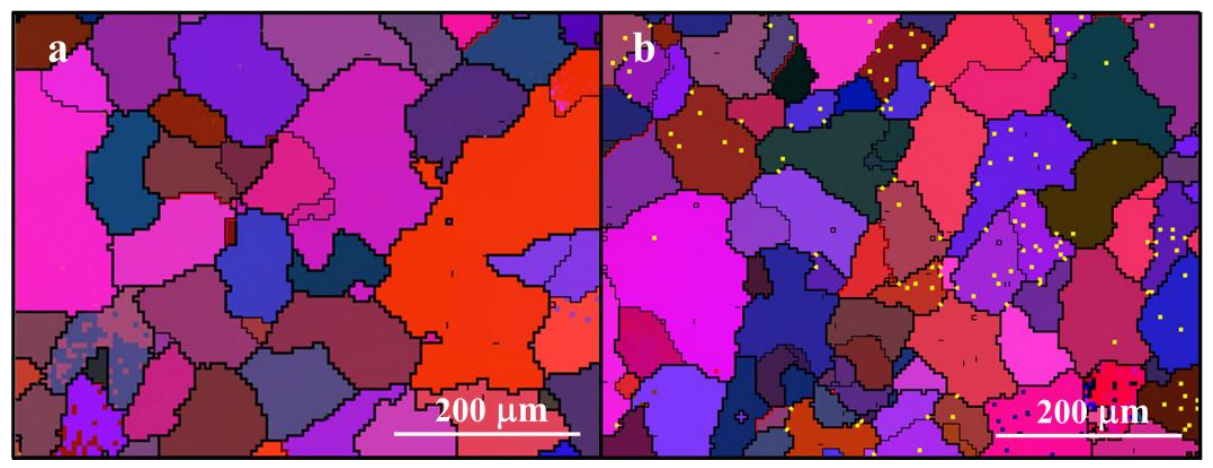

Figure 9. EBSD images of $7075 \mathrm{~T} 6 \mathrm{Al}$ alloy without (a) and with $0.1 \mathrm{wt}$ \% $\%$ Sr additions (b) (yellow dots in the image are set as $\mathrm{Al}_{4} \mathrm{Sr}$ ).

The distinctive feature of the tensile properties of the alloys obeys the Hall-Petch law qualitatively, as Equation (1) shows:

$$
\sigma=\sigma_{0}+k d^{-\frac{1}{2}}
$$

where $\sigma_{0}$ and $k$ are constants that are related to the crystal type and $d$ is the average grain size. Thus, the finer the grain size, the better the mechanical properties. Unfortunately, the grain of $7075 \mathrm{Al}$ changed from nearly globular to lamellar after extrusion; thus, a quantitative statistic of the grain size is difficult to obtain.

When the Sr addition increases to $0.2 \mathrm{wt}$. \% in extruded $7075 \mathrm{Al}$ alloy, the mechanical properties are inferior than the alloy with $0.1 \mathrm{wt}$. \% Sr addition. SEM microstructures of as-cast $7075 \mathrm{Al}$ alloy without and with $0.2 \mathrm{wt}$. \% Sr modification is showed in Figure 6. Microporosity in the alloy with $0.2 \mathrm{wt}$. \% Sr 
modification in show in Figure 10b, which is the main reason for the reduction of mechanical properties after extrusion and T6 heat treatment. While the grain boundary of $7075 \mathrm{Al}$ alloy without Sr addition was very clear (Figure 10a). The increase in the $\mathrm{Al}_{4} \mathrm{Sr}$ volume fraction increases the overall porosity area of the gas pores from $6.2 \%$ to $9.6 \%$, compared with the sample without Sr. This porosity decreases both the yield and ultimate tensile strength values of the produced samples, as Tekman et al. have reported [28,29]. Porosity parameters, namely, the total porosity area is analyzed using Pixcavator IA 4.3 software (Marshall University, Huntington, WV, USA).

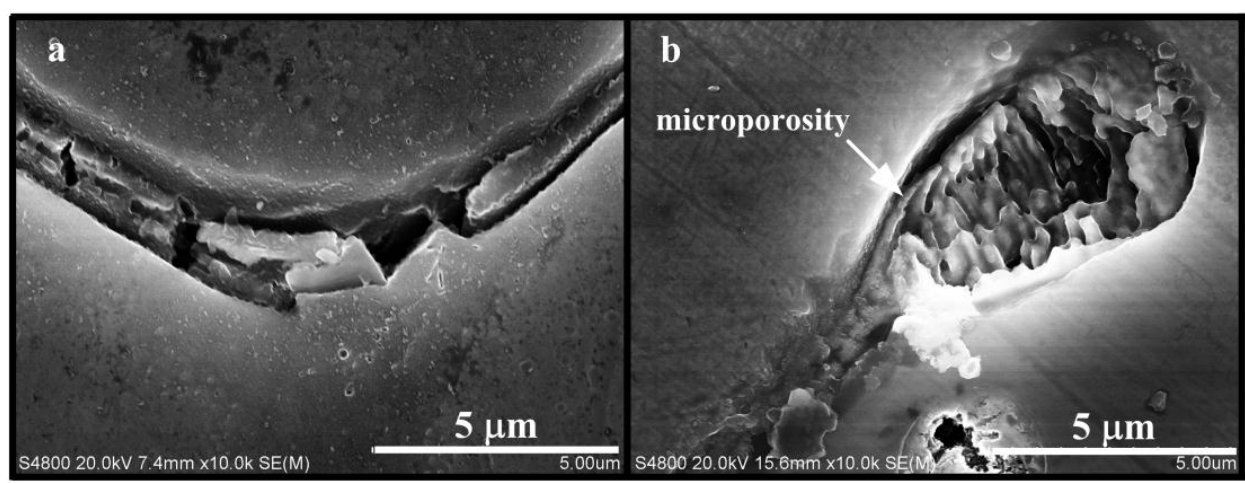

Figure 10. High-magnification SEM images of as-cast $7075 \mathrm{Al}$ alloy without (a) and with $0.2 \mathrm{wt}$. \% Sr (b).

The typical SEM images of the fracture surfaces in Figure 11 reveal a transition from brittle to ductile fracture mode by adding different contents of Sr. The alloy before modification has high fragility, which may cause low tensile strength and elongation. By contrast, the fracture surface of Sr-modified alloy (Figure 11c) shows more and finer dimples, which is to say the rupture has a ductile nature, indicating that the cracks hardly propagated through these precipitates. The morphology of $\mathrm{MgZn}_{2}$ has a critical effect on the mechanical properties of the alloy. The $\mathrm{MgZn}$ 2 particles become finer, and the mechanical properties of the alloy are improved.

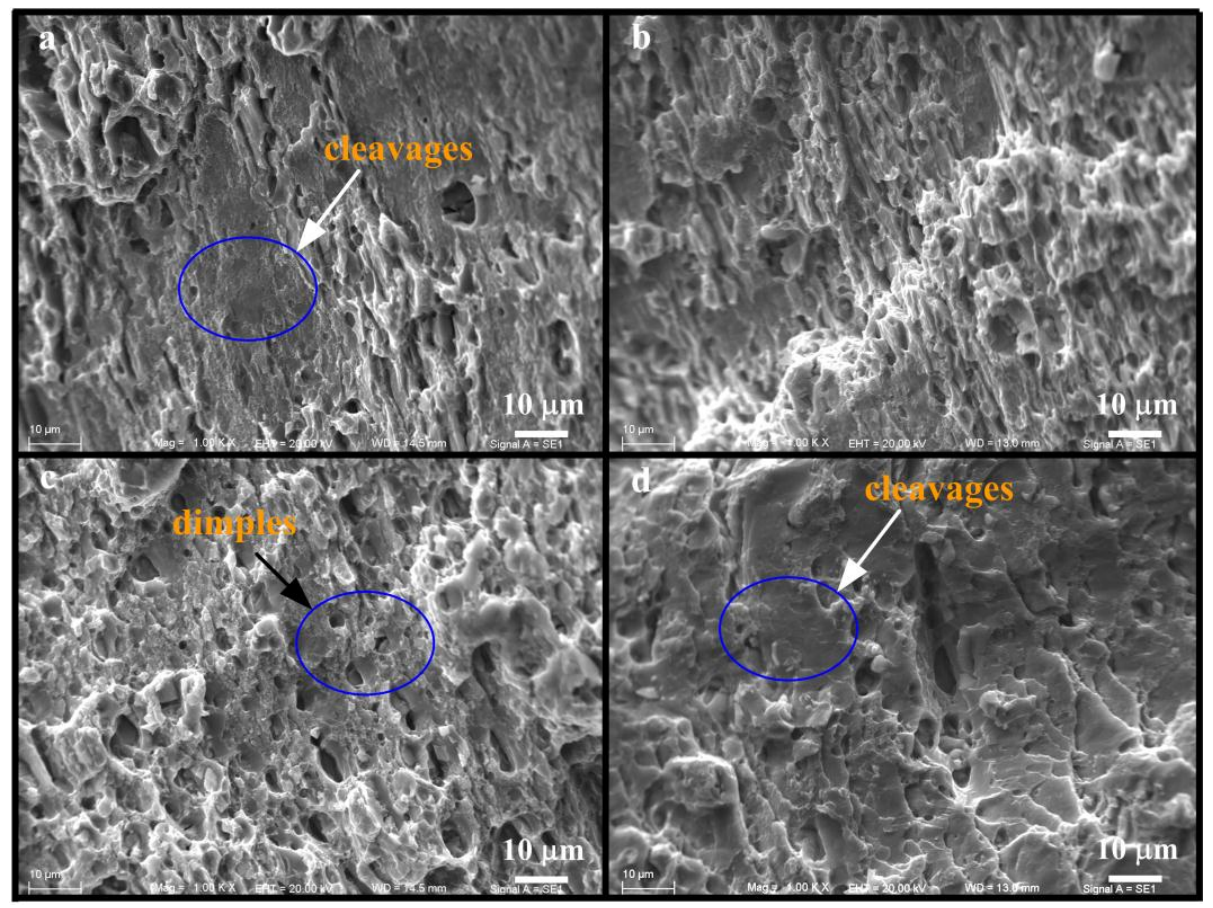

Figure 11. The SEM fracture morphology of 7075 T6 alloy without and with different contents of Sr: (a) 0 wt. \%; (b) 0.05 wt. \%; (c) 0.1 wt. \%; and (d) 0.2 wt. \% Sr. 


\section{Conclusions}

Minor Sr additions have effects on the microstructures of as-cast and $7075 \mathrm{~T} 6 \mathrm{Al}$ alloy. The grain size of both cast and extruded T6 treated $7075 \mathrm{Al}$ alloy was refined by different degrees after adding 0 , $0.05,0.1$ and $0.2 \mathrm{wt}$. \% Sr. The growth of $\alpha-\mathrm{Al}$ was accompanied by the adsorption of $\mathrm{Sr}$ atom to the steps of a solid-liquid interface. The strength phase $\mathrm{MgZn}_{2}$ in extruded $7075 \mathrm{~T} 6$ alloy was also refined and well-distributed after different $\mathrm{Sr}$ addition.

Minor Sr addition have effects on the mechanical properties of extruded $7075 \mathrm{~T} 6 \mathrm{Al}$ alloy. The mechanical properties of extruded $7075 \mathrm{~T} 6 \mathrm{Al}$ alloy were improved at first and then decreased as the Sr addition increased from $0.05 \mathrm{wt}$. \% to $0.2 \mathrm{wt}$. \%. By adding $0.1 \mathrm{wt}$. \% Sr, the ultimate tensile strength of extruded 7075 T6 increased from 573 to $598 \mathrm{MPa}$. Fracture elongation increased from $19.5 \%$ to $24.9 \%$. Microhardness improved from 182 to $195 \mathrm{Hv}$. The fracture mode revealed a transition from brittle fracture to ductile fracture as Sr addition increased from $0.05 \mathrm{wt}$. \% to $0.2 \mathrm{wt}$. \%. The improvement of the mechanical properties was mainly ascribed to the reduction of the grain size and the formation of high melting point phase $\mathrm{Al}_{4} \mathrm{Sr}$, which could act as barriers for dislocation movement.

Acknowledgments: This work is supported by SinoProbe-09-05 (Project No. 201011082), International S\&T Cooperation Program of China (Grant No. 2013DFR70490).

Author Contributions: Youhong Sun conceived and designed the experiments; Shaoming Ma and Chi Zhang performed the experiments; Huiyuan Wang and Yinlong Ma analyzed the data; Ming Qian, Baochang Liu and Xiaoshu Lv contributed reagents/materials/analysis tools; Shaoming Ma wrote the paper.

Conflicts of Interest: The authors declare no conflict of interest.

\section{References}

1. Liang, J.; Sun, J.H.; Li, X.; Zhang, Y.Q.; Li, P. Development and Application of Aluminum Alloy Drill Rod in Geologic Drilling. Process. Eng. 2014, 73, 84-90.

2. Ziomek-Moroz, M. Environmentally Assisted Cracking of Drill Pipes in Deep Drilling Oil and Natural Gas Wells. Mater. J. Eng. Perform. 2012, 21, 1061-1069. [CrossRef]

3. Panigrahi, S.K.; Jayaganthan, R. Effect of ageing on microstructure and mechanical properties of bulk, cryorolled, and room temperature rolled Al 7075 alloy. J. Alloy. Compd. 2011, 509, 9609-9616. [CrossRef]

4. Xu, X.F.; Zhao, Y.G.; Ma, B.D.; Zhang, M. Electropulsing induced evolution of grain-boundary precipitates without loss of strength in the $7075 \mathrm{Al}$ alloy. Mater. Charact. 2015, 105, 90-94. [CrossRef]

5. Fard, R.R.; Akhlaghi, F. Effect of extrusion temperature on the microstructure and porosity of A356-SiC $\mathrm{p}$ composites. J. Mater. Process. Technol. 2007, 187-188, 433-436. [CrossRef]

6. Lü, S.L.; Wu, S.S.; Dai, W.; Lin, C.; An, P. The indirect ultrasonic vibration process for rheo-squeeze casting of A356 aluminum alloy. J. Alloy. Compd. 2012, 212, 1281-1287. [CrossRef]

7. Haghayehi, R.; Heydari, A.; Kapranos, P. The effect of ultrasonic vibrations prior to high pressure die-casting of AA7075. Mater. Lett. 2015, 153, 175-178. [CrossRef]

8. Mapelli, C.; Gruttadauria, A.; Peroni, M. Application of electromagnetic stirring for the homogenization of aluminium billet cast in a semi-continuous machine. J. Mater. Process. Technol. 2010, 210, 306-314. [CrossRef]

9. Pacz, A. Alloy. U.S. Patent 1387900 [P/OL], 16 August 1921.

10. Kyziol, K.; Koper, K.; Sroda, M.; Klich, M.; Kaczmarek, L. Influence of gas mixture during $\mathrm{N}^{+}$ion modification under plasma conditions on surface structure and mechanical properties of Al-Zn alloy. Surf. Coat. Technol. 2015, 278, 30-37. [CrossRef]

11. Liao, C.W.; Chen, J.C.; Li, Y.L.; Chen, H.; Pan, C.X. Modification performance on 4032 Al alloy by using Al-10Sr master alloys manufactured from different processes. Prog. Nat. Sci. Mater. Int. 2014, 24, 87-96. [CrossRef]

12. Liu, G.L.; Si, N.C.; Sun, S.C.; Wu, Q.F. Influence of heat treatment on microstructure and friction and wear properties of multicomponent Al-7·5Si-4Cu alloy. Trans. Nonferr. Met. Soc. China 2014, 24, 946-953. [CrossRef]

13. Shivaprasad, C.G.; Narendranath, S.; Desai, V.; Swami, S.; Granesha, M.S. Influence of Combined Grain Refinement and Modification on the Microstructure and Mechanical Properties of Al-12Si, Al-12Si-4.5Cu Alloys. Procedia Mater. Sci. 2014, 5, 1368-1375. [CrossRef] 
14. Srirangam, P.; Chattopadhyay, S.; Bhattacharya, A.; Nag, S.; Kaduk, J.; Shankar, S.; Shankar, R.; Banerjee, R.; Shibata, T. Probing the local atomic structure of Sr-modified Al-Si alloys. Acta Mater. 2014, 65, 186-193. [CrossRef]

15. Barriero, J.; Engstler, M.; Ghafoor, N.; Jonge, N.; Oden, M.; Mucklich, F. Comparison of segregations formed in unmodified and Sr-modified Al-Si alloys studied by atom probe tomography and transmission electron microscopy. J. Alloy. Compd. 2014, 611, 410-421. [CrossRef]

16. Timpel, M.; Wanderka, N.; Kumar, G.S.V.; Banhart, J. Microstructural investigation of Sr-modified Al-15 wt. \% Si alloys in the range from micrometer to atomic scale. Ultramicroscopy 2011, 111, 695-700. [CrossRef] [PubMed]

17. Bai, J.; Sun, Y.S.; Xun, S.; Xue, F.; Zhu, T.B. Microstructure and tensile creep behavior of Mg-4Al based magnesium alloys with alkaline-earth elements Sr and Ca additions. Mater. Sci. Eng. A 2006, 419, 181-188.

18. Yang, M.B.; Pan, F.S.; Cheng, R.J.; Tang, A.T. Effects of various Mg-Sr master alloys on microstructural refinement of ZK60 magnesium alloy. J. Alloy. Compd. 2008, 461, 298-303. [CrossRef]

19. Binesh, B.; Aghaie-Khafri, M. Phase Evolution and Mechanical Behavior of the Semi-Solid SIMA Processed 7075 Aluminum Alloy. Metals 2016. [CrossRef]

20. Tavighi, K.; Emamy, M.; Emami, A.R. Effects of extrusion temperature on the microstructure and tensile properties of Al-16 wt. \% Al 4 Sr metal matrix composite. Mater. Des. 2013, 46, 598-604. [CrossRef]

21. Ma, K.; Wen, H.; Hu, T.; Topping, T.D.; Isheim, D.; Seidman, D.N.; Lavernia, E.J.; Schoenung, J.M. Mechanical behavior and strengthening mechanisms in ultrafine grain precipitation-strengthened aluminum alloy. Acta Mater. 2014, 62, 141-155. [CrossRef]

22. Sha, G.; Cerezo, A. Early-stage precipitation in Al-Zn-Mg-Cu alloy (7050). Acta Mater. 2004, 52, $4503-4516$. [CrossRef]

23. Nicolas, M.; Deschamps, A. Characterisation and modelling of precipitate evolution in an Al-Zn-Mg alloy during non-isothermal heat treatments. Acta Mater. 2003, 51, 6077-6094. [CrossRef]

24. Barrirero, J.; Li, J.; Engstler, M.; Ghafoor, N.; Schumacher, P.; Odén, M.; Mücklich, F. Cluster formation at the $\mathrm{Si}$ /liquid interface in Sr and Na modified Al-Si alloys. Scr. Mater. 2016, 117, 16-19. [CrossRef]

25. SShin, S.; Kim, E.S.; Yeom, G.Y.; Lee, J.C. Modification effect of Sr on the microstructures and mechanical properties of Al-10.5Si-2.0Cu recycled alloy for die casting. Mater. Sci. Eng. A 2012, 532, 151-157. [CrossRef]

26. Chen, D.C.; You, C.S.; Gao, F.Y. Analysis and Experiment of 7075 Aluminum Alloy Tensile Test. Procedia Eng. 2014, 81, 1252-1258. [CrossRef]

27. Tajally, M.; Huda, Z.; Masjuki, H.H. A comparative analysis of tensile and impact-toughness behavior of cold-worked and annealed 7075 aluminum alloy. Int. J. Impact Eng. 2010, 37, 425-432. [CrossRef]

28. Tekmen, C.; Ozdemir, I.; Cocen, U.; Onel, K. The mechanical response of Al-Si-Mg/SiC p composite: Influence of porosity. Mater. Sci. Eng. A 2003, 360, 365-371. [CrossRef]

29. Farhoodi, B.; Raiszadeh, R.; Ghanaatian, M.H. Role of Double Oxide Film Defects in the Formation of Gas Porosity in Commercial Purity and Sr-containing Al Alloys. J. Mater. Sci. Technol. 2014, 30, 154-162. [CrossRef]

(c) 2017 by the authors; licensee MDPI, Basel, Switzerland. This article is an open access article distributed under the terms and conditions of the Creative Commons Attribution (CC-BY) license (http://creativecommons.org/licenses/by/4.0/). 